\title{
Impact of COVID-19 and Related Forced Digitalization Processes on the Competitiveness of Higher Education Institutions and Organizations
}

\author{
Natalia Pashkus ${ }^{1, *}$, Polina Bavina $^{2}$, Elena Egorova ${ }^{2}$ \\ ${ }^{1}$ Herzen State Pedagogical University, Institute of Economics and Management, Department of \\ Industrial Economics and Finance, the Moika river emb., 48.St. Petersburg, Russia \\ ${ }^{2}$ Herzen State Pedagogical University, Institute of Economics and Management, Department of \\ Social Marketing, the Moika river emb., 48.St. Petersburg, Russia
}

\begin{abstract}
.
Research background: One of the areas that has undergone major changes in the processes of its activities and has had a strong impact on the change in social institutions is the field of education. The sharp transition to distance education and a number of technical, informational and human problems led to a significant complication of educational and other processes (scientific, innovative, entrepreneurial, etc.).

Purpose of the article: The article raises the problem of the impact of the coronavirus pandemic on global social and public institutions. The purpose of the article is to identify the factors of ensuring the competitiveness of universities, as the least protected by state support, in the context of forced digitalization against the background of the covid-19 pandemic.

Methods: The paper uses mechanisms for assessing the competitiveness of universities in the new reality of the pandemic and its consequences, implemented on the basis of a modified McKinsey matrix and matrix algorithms for evaluating priority vectors.

Findings \& Value added: The analysis showed that the universities that have the greatest independence in the system face the greatest difficulties in carrying out their activities in the context of a pandemic. As scientific growth can be considered, the results of the analysis of the transition to distance learning processes that have combined higher education systems in different countries, and if earlier most universities competed at the regional or country level, now they are forced to enter into global competition with foreign universities.
\end{abstract}

Keywords: higher education; universities; competitiveness matrix; COVID-19

JEL Classification: $I 25 ; M 31$

${ }^{*}$ Corresponding author: nat pashkus@mail.ru 


\section{Introduction}

In the context of the covid-19 pandemic, the education systems of the countries faced serious problems of normal functioning. Restrictive measures have led to the need for forced introduction of digital technologies to ensure the educational process. And if before the pandemic, digitalization was presented as a universal good that will solve all the problems of education and will completely eliminate the face-to-face phases of communication with the teacher, will ensure an individual approach to students and will be an exceptional universal good [ 1 -3], during the pandemic, many of the myths of digitalization were debunked. As the experience of forced digital interaction with students, as well as the experience of remote control of educational processes and administration of educational institutions, has shown, digitalization has not become a panacea, although some elements of digital education have proved their success and earned the right to exist [4]. But the conclusion that absolutely all interested parties recognized is that it is impossible to replace classical education with digital education.

School education has suffered the most from the forced transition to digitalization, where the quality of educational services has fallen sharply, and parents have suffered a terrible blow from the additional burden of educating their children at home and reporting to schools about their learning process at home. Most parents in different regions of Russia are not satisfied with the distance education of their children. Only $2 \%$ of parents, usually whose children study in elite high schools and specialized specialized schools, did not notice a special difference when switching to distance education. At the same time, most teachers also experience difficulties from switching to distance education, as their workload has increased dramatically, they have become forced to contact students, their parents and school management almost around the clock, which, taking into account the General nervous situation, provoked mass stress and caused a further drop in the quality of education. At the same time, the school was in the center of public attention. Indeed, many families were not prepared for this turn of events and could not provide their children with everything necessary for distance education. In addition, sometimes parents switched to remote work, so both children and parents had to share home devices to access the Internet. Many regions have organized collections of tablets, computers, mobile devices and other items of equipment to provide students with the opportunity to access the Internet at the proper level. The state allocated funds for the purchase of additional equipment to provide teachers and students, and funds for the retraining of teachers and teachers. Note that research confirms the effectiveness of this experience [5,6]. However, the financial capabilities of regions and municipalities are different. And, if in large cities, in most cases, the situation with technical support was better, in small settlements, distance education actually led to the termination of schools. A similar situation was observed in a number of countries around the world, which were also not ready for such a development.

During the period of restrictive measures due to the coronavirus pandemic, school education received the largest subsidies and assistance from the state and society, but the higher education system was funded "on a residual basis". Universities, on the one hand, were almost ready to switch to distance education, due to existing requirements and due to the experience of digitalization, but, on the other hand, faced no less, and sometimes more difficulties during the pandemic. To ensure high quality of educational services, universities had to significantly develop their e-learning platforms, which were not designed for such a volume of operation at peak loads. Moreover, it was necessary to develop fundamentally new principles of remote work with the necessary equipment for teaching and conducting scientific activities of students, postgraduates and University employees. Universities faced very serious difficulties in the administration and management of the main business processes. If remote platforms were still designed for educational activities, then remote 
management and support of all administrative processes in most universities was practically not established. The University is a very large social structure, which makes it difficult to coordinate and creates a number of barriers to interaction when working remotely.

In contrast to commercial structures, higher education institutions usually did not have the level of resources to provide employees and students with the necessary equipment and software. Most universities have placed their bets on free electronic platforms and resources. Thus, both teachers and students faced problems with technical equipment, as home appliances did not always cope with the constant peak load, failing or giving failures. In addition, due to the abrupt transition to distance learning and the introduction of restrictive measures, the situation was unpredictable for many, some of them found themselves visiting relatives or friends, where it was not always possible to equip a stationary workplace. There were cases when people went on vacation and were locked up in other countries. Some students lost their jobs during the pandemic and were unable to support themselves, and the situation was particularly difficult for non-resident students who were deprived of their means of subsistence during this period. In fact, all these problems directly or indirectly fell on the University, which had to individually consider all situations in which students could not participate in distance education for technical or financial reasons.

Another serious challenge for higher education institutions was the unpredictable policies of the education authorities, which constantly fluctuated in their decisions and constantly gave contradictory instructions. University rectors, fearing criticism from the education authorities and relevant ministries, also delayed vital decisions regarding the organization of the educational process, passing state certification, and the schedule of graduation and entrance tests. All this negatively affected the quality of the educational process, the motivation of employees, and the coordination of activities in the organization as a whole. Moreover, even universities with strong brands and high demand in the market of educational services faced this problem and partially discredited themselves. Unfortunately, most universities have shown an inability to properly control the process of distance education and effectively manage this complex structure remotely.

Due to the above-mentioned problems that manifested themselves during the pandemic, the competitiveness of universities could suffer greatly. This year, due to remote recruitment, leading universities did not meet any obstacles in recruiting students for various levels of education, although regional universities have already been forced to announce additional recruitment. There were also problems in recruiting students on a paid basis, especially for master's and postgraduate programs. Moreover, applicants were able to choose not only between Russian universities, but also educational programs of foreign universities that also implement distance programs. Many foreign higher education institutions began to learn distance learning earlier, as a result of which they were better prepared for the current situation, and in these conditions they began to expand into new markets. Moreover, these universities are often part of a strong cultural brand of the territory, which has significantly increased their competitiveness [7]. All this had a negative impact on the competitive performance of many Russian universities.

\section{Methodology}

In General, it should be noted that the typical characteristics of the University's competitiveness in these new conditions for the education system require serious improvement. Negative aspects of the work of universities and not the alignment has caused not only frustration among staff and students, but also affected the image of institutions of higher education, and in the future could reduce their competitive position. Therefore, it is necessary to Refine the system for assessing the competitiveness of universities, taking into account new factors of strong influence for them. The strongest influence in the context of 
the pandemic was a factor that could be described as the stress resistance of the University management system. Indeed, those universities that demonstrated a calm, well-coordinated work, almost imperceptible transition from face-to-face presence to remote forms of education, caused fewer complaints from all contact persons, and suffered fewer losses. Losses of higher education institutions in modern conditions could be caused by instability of processes, refusal to actively innovate, inability to coordinate work at the appropriate level, loss of image, loss of students who are unable to pay for their education in the current period, and loss of applicants who transferred to another Russian or foreign University offering distance education programs. In particular, many higher education institutions that previously attracted a large number of foreign students are experiencing difficulties in educating foreign citizens due to closed borders, poor coordination of the distance education process and its instability. Consequently, the problem of coordination and efficiency of education management becomes a key issue for higher education institutions during this period. Another important factor is the ability to implement and coordinate innovation activities in crisis conditions and peak loads on the system caused by distance education. Thus, these factors should be included in the system of assessing the competitive position of the University and taken into account when identifying its long-term strategy of behavior in the global market of educational services.

To build a system for assessing the competitive position of a University, you should set high-quality multi-criteria assessments, expressed in the form of vectors that determine the most important parameters of the competitive position of the University in the current conditions. For this purpose, we should apply a model for assessing the competitive status of a University based on modified strategic models, in particular, the GE/McKinsey model (see figure 1).

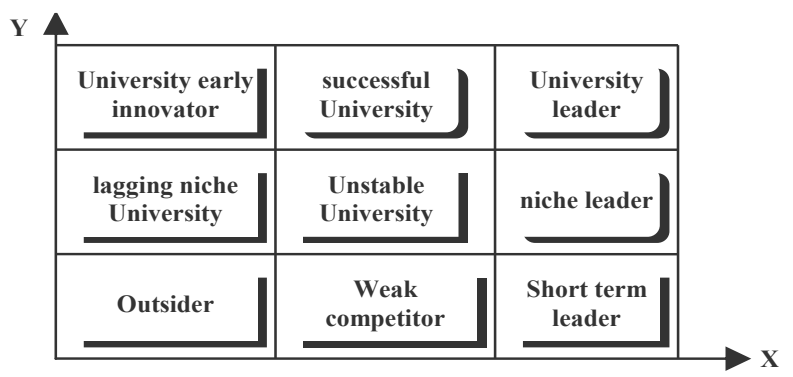

Fig. 1. The matrix of competitiveness of universities

Shown in Fig. 1 the areas of competitiveness of higher education institutions involve different approaches to the formation of a long-term strategy of market behavior. The first group is Universities that have a winning competitive position. It is important for a leading University to maintain its position in the market. Therefore, the main efforts of such a University should be aimed at ensuring an attractive image and strengthening the brand of the University. And, most importantly, for the leader at the current stage-ensuring high stress tolerance of the University management system. A successful University should soberly assess its strengths and weaknesses and identify a reasonable way to strengthen its market position and develop its brand in the light of its resource potential. A niche leader must identify an attractive market niche and follow the path of narrow specialization. The second group of universities: these are "intermediate" ones, where organizations that are in the transition stage between lagging and succeeding Are concentrated. The intermediate position is very unstable and where the strategic trajectory of development will go is currently unclear. These Universities make significant efforts to protect their segment from attacks from competitors of all types. An early innovator is actually at the beginning of the brand 
development path, and the prospects for such a University have not yet been determined. The third group of universities is lagging behind. An unstable University is in the most precarious position, because at the slightest change in the market, it may not be able to withstand competition. A short-term leader is such due to the high probability of a sharp closure of its business line. A lagging niche University needs to be protected from the impact of risks and is often not effective enough to attract large amounts of budget funding, grant flows, and provide a high proportion of students studying on a fee-based basis, if it does not dump prices on its educational services. A weak competitor is actually constantly losing the market, which in the absence of effective measures can lead to the collapse of the University. And finally, the outsider gets into a crisis area, being in which means for the University the need to use all available resources to get out of the crisis situation.

The system of criteria that should be used to evaluate University performance, taking into account current environmental requirements, is undergoing certain changes. The following characteristics of a University's competitive status (X) can be critical indicators for a University in a pandemic:

1. The relative market share of higher education services for the selected main profile of the University;

2. The ability to provide high real and perceived quality of educational services, the prestige of the University;

3. The ability to provide additional funding to the University by recruiting students for extra-budgetary places in educational programs at all levels, attracting funded projects and grants to the University, entrepreneurship and commercialization of the results of innovative activities of employees and students of the University;

4. The ability to attract and maximize the human potential of leading specialists of the teaching staff, as well as research specialists;

5. The uniqueness of the resource potential of the University and implemented them in their profile, level of innovative potential and ability to foster the implementation of innovative activities by all categories of employees and students of the University;

6. The level of technological and material-technical equipment of educational and innovative processes in an educational organization;

7. The share of budget educational programs and the volume of target enrollment in popular educational areas to ensure the level of accessibility of educational services of the University for the population;

8. The level of development of electronic and informational support of the University's activities and the quality of the organization of the distance learning process;

9. University Rating and stability of its position in domestic and international rating systems;

10. The volume and amount of subsidies, grants and other additional financial resources attracted to the University;

11. Stress tolerance and the ability to control the effectiveness of work in conditions of high loads, forced distance education and additional requirements for the work of the University and all its departments in a pandemic.

Forming an assessment of the University's position on the competitiveness matrix requires setting a system of criteria for evaluating the attractiveness of the educational services market for the main or selected for analysis direction of the University (Y):

1. Potential capacity of the market of educational services of this profile in the region;

2. features of competition in the selected segment of educational services of the University;

3. Potential dynamics of the volume of educational services provided on a paid basis; 
4. Amounts of grant funds in the areas in which the University is a recognized competent and their dynamics;

5. Restrictions and requirements for the University's innovative developments and research and public and private investments attracted for their development;

6. Requirements for the development of the electronic environment, information and remote support of University activities;

7. Requirements of the Federal standard and educational supervision and management bodies for the implementation of educational and additional activities of the University, in particular, in the context of a pandemic;

8. The level of risks of conducting educational activities and potential threats to the stability of the existence of universities;

9. The level of uncertainty and variability of the external environment in which higher education institutions have to work.

To assess the competitive position of a University, integral characteristics of the competitive status and attractiveness of the market of each University are used, the convolution of which is carried out by using marginal replacement coefficients for each evaluation criterion expressed by vector characteristics. To build integral characteristics of a University's competitive position, you can use the procedure for forming interaction matrices for each evaluation criterion (see formula (1)).

So, if $\mathrm{n}$ is the number of criteria, and $\mathrm{t}$ is the number of analyzed universities, then matrices

\begin{tabular}{|c|c|}
\hline & $\left(\begin{array}{ccc}b_{11}^{1} & \ldots & b_{1 m}^{1} \\
\ldots & \ldots & \ldots \\
b_{m 1}^{1} & \ldots & b_{m m}^{1}\end{array}\right)$ \\
\hline In be constructed for each evaluation criterion: & $\left(\begin{array}{ccc}b_{11}^{2} & \ldots & b_{1 m}^{2} \\
\ldots & \ldots & \ldots \\
b_{m 1}^{2} & \ldots & b_{m m}^{2}\end{array}\right)$ \\
\hline & $\left(\begin{array}{ccc}b_{11}^{n} & \ldots & b_{1 m}^{n} \\
\ldots & \ldots & \ldots \\
b_{m 1}^{n} & \ldots & b_{m m}^{n}\end{array}\right)$ \\
\hline
\end{tabular}

To obtain integral estimates of the competitive status of the University and the attractiveness of its market, it will be necessary to obtain auxiliary characteristics of the influence of the selected criterion for each evaluation matrix (see the formula (2), (4), (6)). For the first criterion, the scores are constructed as roots of degree $\mathrm{m}$ :

$$
\begin{aligned}
& B_{1}^{1}=\sqrt[m]{b_{11}^{1} \cdot b_{12}^{1} \ldots \cdot b_{1 m}^{1}} \\
& B_{2}^{1}=\sqrt[m]{b_{21}^{1} \cdot b_{22}^{1} \ldots \cdot b_{2 m}^{1}} \\
& \cdots \cdots \cdots \cdots \cdots \cdots \cdots \cdots \cdots \cdots \\
& B_{m}^{1}=\sqrt[m]{b_{m 1}^{1} \cdot b_{m 2}^{1} \ldots \cdot b_{m m}^{1}}
\end{aligned}
$$

As a result, an integral vector estimate of the priority of each influence criterion can be obtained for each matrix (see the formula (3), (5), (7))

According to the first criterion, the integral characteristic of competitiveness will be: 


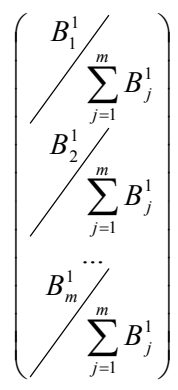

(3)

According to the following criteria, integral characteristics are evaluated in the same way:

$$
\begin{aligned}
& B_{1}^{2}=\sqrt[m]{b_{11}^{2} \cdot b_{12}^{2} \ldots \cdot b_{1 m}^{2}} \\
& B_{2}^{2}=\sqrt[m]{b_{21}^{2} \cdot b_{22}^{2} \ldots \cdot b_{2 m}^{2}} \\
& \text { (4) and } \\
& \left(\begin{array}{c}
B_{j=1}^{2} B_{j}^{m} \\
B_{2}^{2} / m \\
\sum_{j=1}^{m} B_{j}^{2} \\
B_{m}^{2} \cdots \\
\sum_{j=1}^{m} B_{j}^{2}
\end{array}\right), \ldots, \\
& B_{m}^{2}=\sqrt[m]{b_{m 1}^{2} \cdot b_{m 2}^{2} \ldots \cdot b_{m m}^{2}} \\
& \left(\begin{array}{c}
\sum_{j=1}^{n} B_{j}^{n} \\
B_{2}^{n} \sum_{j=1}^{m} B_{j}^{n} \\
B_{m}^{n} \cdots \\
\sum_{j=1}^{m} B_{j}^{n}
\end{array}\right) \\
& B_{1}^{n}=\sqrt[m]{b_{11}^{n} \cdot b_{12}^{n} \ldots \cdot b_{1 m}^{n}} \\
& B_{2}^{2}=\sqrt[m]{b_{21}^{n} \cdot b_{22}^{n} \ldots \cdot b_{2 m}^{n}} \\
& B_{m}^{2}=\sqrt[m]{b_{m 1}^{n} \cdot b_{m 2}^{n} \ldots \cdot b_{m m}^{n}}
\end{aligned}
$$

The obtained integral estimates of the competitive status and attractiveness of the University market should be applied to the plane of the competitiveness matrix and determine the current position of the University in its competitive environment. We will show the application of this model to Saint Petersburg universities.

\section{Results}

The proposed model can be used to determine the comparative competitive positions of several universities in St. Petersburg that have a similar profile of activity and work in the same market of educational services. It should be noted that some universities use monospecialization, but a significant proportion of them are polyspecialized. In this regard, when comparing competitive positions, it is necessary to choose monospecialized universities and separate educational areas of polyspecialized ones. For analysis, select the following educational organizations and their divisions:

1. Faculty of Economics and Higher school of management of St. Petersburg state University (SPbU) (1)

2. HSE, Saint Petersburg branch (2) 


\section{UNECON (Saint Petersburg State University of Economics established on the basis of} FINEC) (3)

4. Institute of Economics and management of the Herzen state pedagogical University (Herzen University) (4)

All these universities demonstrate a high quality of training in economic and managerial fields, have established practice in this area of training, have experience and developed resource potential for training students, including in a complex epidemiological situation characterized by additional requirements for the activities of universities. All these institutions demonstrated a high rate of adaptation to the new conditions of remote activity in the event of an emergency transition to remote work. Graduates of these educational institutions of this professional profile are in demand in the labor market of St. Petersburg and Russia as a whole.

We will conduct a comparative analysis of these medical institutions in the city and identify promising areas for their strategic development in the context of the pandemic. Using the system of criteria introduced above, we will evaluate marginal replacement coefficients for the competitive status and attractiveness of the market for all six universities. The obtained characteristics for all organizations are plotted on the area of the competitiveness matrix. The analysis showed that three of the University, or rather the economic faculty and the school of management SPbU, HSE and the St. Petersburg state economic University took on this aspect of training leading positions. SPbU has become a leading University, while HSE and SPbU have become niche leaders, although their positions are close to the leading field. These results reflect the current competitive position of higher education institutions, which clearly took place before the pandemic. The transition of the HSE and UNECON to the category of niche leaders is related to their internal problems rather than to the development and course of the pandemic and the associated period of remote work. Thus, the HSE, as a structural division and branch of the Moscow University, cannot independently implement an Autonomous strategy, and the strategy of the University as a whole in St. Petersburg requires some adaptation to the environment. SPbU, in turn, during the stage of merger and restructuring showed certain defects in coordination and reduced quality characteristics of its activities. Consequently, SPbU should pay attention to maintaining and further strengthening its position in this professional area of training. HSE needs to identify new promising areas of the chosen professional field and position itself within the framework of related training areas. The problem is that the bulk of research is initiated and conducted by the Moscow division of the University, while the branch in St. Petersburg mainly performs the role of a slave. FINEC should make efforts to strengthen its competitive status, of all investigational leaders he is closest to the unstable area universities, which in the future may fall competitive status and declining prestige of the University. During the pandemic and the difficulties of remote work, negative trends in higher education institutions may be exacerbated by a decrease in the effectiveness of coordination of processes, for example, within research groups, and a slowdown in innovation activity. The transition to forced distance education is fraught with loss of communication with students, which can negatively affect the quality of educational activities. Thus, these trends can further shake the position of the University. Herzen University is an early innovator in this area, and it has come to the border of a successful University, although it may have partially lost its position on the contrary. At the same time, the potential attractiveness of the market in this area for the Herzen University is still not high enough, the University has only passed the border of the successful zone, but is still quite close to the zone of lagging universities. Thus, Herzen University needs to find its own attractive segment of the educational services market and strengthen its position in it, including by applying the strategy of building an umbrella brand that protects this area of training, which is often perceived as unprofessional at the present time. 


\section{Discussion}

This model allows you to assess the competitiveness of Universities. However, there are certain limitations regarding both its application and the use of the results of the model in determining economic and social policy priorities.

First, this model is designed to assess the competitive position of monospecialized universities (or monospecialized divisions of polyspecialized universities). However, there is still a problem with assessing the competitiveness of the University as a whole (which is often allocated funds) - as a rule, the competitive position of the University as a whole is evaluated $[8,9]$. Also, based on this model, it is impossible to evaluate innovative educational programs, the contribution of which to the cultural brand of the city can be significant [10, $11]$.

Second, the competitiveness of universities, especially monospecialized ones, depends on a significant number of external factors that are not taken into account by the model [12, 13]. For example, the choice of a particular educational program may depend on the desire to get married or make the right acquaintances [14], as well as the fashion that provokes distorted ideas about the result of mastering the educational program [15]. In addition, let's not forget that University funding also depends on political factors: politicians make "forced" decisions that allow them to stay in power, and the external effects for universities from such decisions can be ambiguous $[16,17]$. Funding also depends on the state of the system as a whole, and the strategic directions of its development, and the direction of policy in General may not coincide with competitive factors for Universities [18-20]. Note that attempts to optimally allocate resources and minimize risk may lead to results that do not match the model [21, 22].

\section{Conclusion}

Application of the model of competitiveness of universities and consideration of new factors has allowed to reveal directions of their strategic development and to draw attention to the bottlenecks currently in the universities strategy. The implemented model of University competitiveness can show both educational institutions and their partners and competitors what factors should be paid attention to, and which development dominants should be put forward as strategic priorities. Those universities in St. Petersburg that were able to demonstrate high performance in the context of the covid-19 pandemic and forced remote activities, maintain the volume of attracted projects and the number of events held, while maintaining the quality of performance in all areas, during this period were able not only to reduce, but also to strengthen their market positions.

\section{References}

1. Kamenica E. (2017). Information Economics. Journal of Political Economy, 125(6), 1885-1890.

2. Polachek, S.W., Das, T., Thamma-Apiroam, R. (2015). Microand Macroeconomic Implications of Heterogeneity in the Production of Human Capital. Journal of Political Economy, 123(6), 1410-1455.

3. Zhang, Y.C.L. (2018). Human Capital, Technology Adoption and Firm Performance: Impacts of China's Higher Education Expansion in the Late 1990s. The Economic Journal, 128(614), 2282-2320.

4. Kushcheva N.B, Terekhova V.I. (2020) Anti-Crisis Digitalization of Higher Education in the Context of Coronavirus Pandemic. Problems of modern economy, 2(74), 255-258. 
5. Mbiti, I. et al. (2019) Inputs, Incentives, and Complementarities in Education: Experimental Evidence from Tanzania. The Quarterly Journal of Economics, 134(3), 1627-1673.

6. Abbott, B., Gallipoli, G., Meghir C., Violante G. L. (2019) Education Policy and Intergenerational Transfers in Equilibrium. Journal of Political Economy, 127(6), 25692624.

7. Pashkus, N.A. et al. (2019). Cultural City Brands and Global Competitiveness. Revista San Gregorio, 36, 197-209.

8. Khalin, V.G., Chernova, G.V. (2015). Jamil Salmi Model of Establishing World-Class Universities and Implementation of Salmi Model for Higer Education in Russia. In: Systems Analysis in Engineering and Management. Proceedings of the XVIII International scientific and practical conference, 160-170.

9. Belov, A. et al. (2018). Universities' Competitiveness Models in Academic Management: a National-Level Approach. Management Theory And Studies for Rural Business and Infrastructure Development, 40(2), 155-166.

10. Pashkus, N. A., Pashkus, V. Y., Bavina, P. A., Yegorova, E. V., \& Volkova, A. V. (2020). Additional Education In The Context Of Modern Art Market Development And The Formation Of Strong Cultural Brands. Revista Tempos e Espaços em Educação, 13(32), 1-15.

11. Koltsova A., Alpatov G., Volkova A. (2020) Culture in the Global Economy: Features of Cultural Goods on the Threshold of a Knowledge Economy And Increasing the Country's Competitiveness. SHS Web of Conferences, 74, 01015.

12. Heckman J.J., Humphries J.E., Veramendi G. (2016). Returns to Education: The Causal Effects of Education on Earnings, Health, and Smoking. Journal of Political Economy,126(S1), S197-S246.

13. Alpatov, G. E., \& Bortnikova, H. G. (2016). Globalization and the unification of tertiary education. Globalization and its Socio-Economic Consequences, 5, 25-32.

14. Chiappori P.-A., Costa Dias M., Meghir C. (2018) The Marriage Market, Labor Supply, and Education Choice. Journal of Political Economy, 126(S1), S26-S72.

15. Heidhues, P., Kőszegi, B., Strack, P. (2018) Unrealistic Expectations and Misguided Learning. Econometrica. 86(4), 1159-1214.

16. Harstad, B. (2020) Technology and Time Inconsistency. Journal of Political Economy, 128(7), 2653-2689.

17. Elliott, M., Golub, B. (2019) A Network Approach to Public Goods. Journal of Political Economy, 127(2), 730-776.

18. Bowles, S. (1967). The Efficient Allocation of Resources in Education. The Quarterly Journal of Economics, 81(2), 189-219.

19. Vertakova, Y.V., Ershova, I.G., \& Plotnikov V.A. (2013). Educational system influence on knowledge economy formation. World Applied Sciences Journal, 27(5), 679-683.

20. Korhonen, I., Lyakin, A.N. (2017). Problems and Prospects of Russia's Economic growth. Bulletin of St. Petersburg University. Economy, 33(1), 36-50.

21. Al-Najjar, N. I., Pomatto, L. (2020) Aggregate risk and the Pareto principle. Journal of Economic Theory. 189, 105084.

22. Kliestik, T., Dengov, V. (2015). Quantitative Approach to Risk as a Social Phenomenon. Applied Social Science, 80, 28-33. 